\title{
Motor recovery after acute ischaemic stroke: a metabolic study
}

\author{
V Di Piero, F M Chollet, P MacCarthy, G L Lenzi, R S J Frackowiak
}

\begin{abstract}
The metabolic changes occurring after ischaemic stroke were measured to investigate the functional anatomy of clinical motor recovery. Positron emission tomography (PET) and the steady-state ${ }^{15} \mathrm{O}$ technique was used to compare resting relative metabolic distributions at the onset of functional deficit with those following recovery. Ten patients were studied with repeat scans. Motor recovery was associated in some patients with an increase of relative oxygen metabolism in anatomical structures normally involved in motor function in the affected hemisphere, particularly in the cortical motor areas. In those patients without such metabolic changes in the cortex of the diseased hemisphere, relative increases in cortical metabolism in the contralateral hemisphere were associated with better motor recovery than in patients with no relative cortical metabolic increase in either hemisphere. There was no correlation between the degree of improvement in motor function and the severity of motor deficit at onset, the size and site of the lesion and the metabolic changes in the infarcted zone. No particular pattern of global metabolic changes was observed after recovery. Thus different relative patterns of metabolic recovery were seen in patients with different lesions and evidence was found for the participation of contralateral structures in the recovery process in some patients.
\end{abstract}

\section{(F Neurol Neurosurg Psychiatry 1992;55:990-996)}

A demonstrably effective therapeutic approach to acute cerebral ischaemia has still to be defined. This is partly due to an incomplete understanding of the mechanisms leading to ischaemic cell death and partly to an even greater ignorance about the mechanisms of functional recovery following cerebral infarction. Research in the area of functional rehabilitation is doubly difficult because of the multiple variables that affect outcome and the difficulty of selecting homogeneous patient populations with respect to mechanism and extent of infarction. ${ }^{1}$ Methods of selecting groups of patients that might benefit from intensive rehabilitation treatment and what forms, if any, such treatment should take remain to be defined. One step would be the establishment of the functional anatomical basis for such recovery. The investigation of such aspects of human functional recovery has been mainly clinical and pathological with attention directed principally at the ischaemic lesion. The results have been contradictory. ${ }^{2-5}$

Cerebral blood flow (CBF) has been the principal functional parameter investigated with the development of functional neuroimaging techniques. However, in the acute phase of stroke there is profound mismatch between cerebral metabolism and blood flow with various degrees of relative or absolute hyperaemia, ${ }^{6-8}$ which means that CBF does not reflect cerebral function in the early phase of injury. The mismatch is responsible for the low prognostic value of $\mathrm{CBF}$ unless the measurement is made within a very few hours of onset of the acute ischaemia. ${ }^{9-11}$ Positron emission tomography (PET) can be used to measure human brain metabolism in vivo thus providing more direct evidence of cerebral function in the acute phase of stroke.

The aim of our study was to evaluate the metabolic changes occurring after ischaemic stroke in the acute and recovered phase and to investigate correlations with clinical recovery of motor function.

\section{Materials and methods}

We studied 5 male and 5 female patients, mean (SD) age $54.3(8.7)$ years, presenting with motor dysfunction due to acute ischaemic infarction in a cerebral hemisphere. Comatose patients or those suffering from other neurological conditions were excluded. The study had the approval of the Hammersmith Hospital ethics committee and the Administration of Radioactive Substances Advisory Committee of the Department of Health, UK. Written informed consent was obtained in each case from the patient or the nearest relative. All but one patient (case 8-table 1) had no history of cerebrovascular disease. Clinical evaluation included a full neurological examination, an assessment of motor function using the motricity index (MI) of Demeurisse et al, ${ }^{12}$ of general function using the Barthel scale, ${ }^{13}$ a Mini Mental State test ${ }^{14}$ and a formal neuropsychological evaluation. The MI is a published scale based upon the MRC grading of muscle strength, especially designed to evaluate "patients' progress in motor recovery ... and correlations with other clinical data". ${ }^{12}$ The scale reflects motor performance using three movements in each limb with appropriate weighting to give a $0-100$ scale, with 100 representing normality. Scores from 0 to 32 
Table 1 Clinical presentation

\begin{tabular}{|c|c|c|c|c|c|c|c|c|c|c|c|}
\hline$N$ & Age & Sex & $\begin{array}{l}\text { Days from } \\
\text { stroke onset }\end{array}$ & Clinical presentation & $\begin{array}{l}C T \text { or MRI scan } \\
\text { lesion }\end{array}$ & Size & $\begin{array}{l}\text { Time } \\
\text { interval to } \\
\text { second scan }\end{array}$ & Residual deficit & $\begin{array}{l}\text { Motricity } \\
I\end{array}$ & $\begin{array}{l}\text { Index } \\
\text { II }\end{array}$ & Other clinical data \\
\hline 1 & 62 & $\mathrm{~m}$ & 3 & $\begin{array}{l}1 \text { Facio-brachial } \\
\text { paresis } \\
1 \text { arm hypoesthesia }\end{array}$ & $\begin{array}{l}\mathrm{r} \text { fronto-temporo- } \\
\text { parietal }\end{array}$ & 1 & 202 & $\begin{array}{l}\text { Minor difficulties } \\
\text { fine finger } \\
\text { movements and } \\
\text { hand hypoesthesia }\end{array}$ & 88 & .100 & $\begin{array}{l}\text { Doppler normal } \\
\text { previous myocardial } \\
\text { infarct }\end{array}$ \\
\hline 2 & 62 & $\mathrm{f}$ & 3 & $\begin{array}{l}1 \text { Hemiparesis } \\
1 \text { Hypoesthesis and } \\
\text { constructional } \\
\text { apraxia }\end{array}$ & $\begin{array}{l}\text { r Internal capsule } \\
(\mathrm{MR})\end{array}$ & $\mathbf{s}$ & 150 & $\begin{array}{l}\text { Increased tone and } \\
\text { hypoesthesia }\end{array}$ & 92 & 100 & $\begin{array}{l}\text { High blood pressure } \\
\text { doppler I int carotid } \\
\text { stenosis }\end{array}$ \\
\hline 3 & 53 & f & 1 & 1 Hemiparesis & r Internal capsule & $\mathbf{s}$ & 121 & $\begin{array}{l}\text { Mild weakness } 1 \\
\text { finger abduction }\end{array}$ & 71 & 100 & Angina \\
\hline 4 & 58 & $\mathrm{f}$ & 5 & 1 arm paresis & \multirow{2}{*}{$\begin{array}{l}\mathrm{r} \text { Internal capsule } \\
\text { and thalamus (MRI) } \\
1 \text { Corona radiata } \\
\mathrm{r} \text { White matter } \\
\text { lucencies (MRI) }\end{array}$} & $\mathbf{s}$ & 60 & $\begin{array}{l}\text { Increased tone and } \\
\text { paresthesiae }\end{array}$ & 72 & 86 & High blood pressure \\
\hline 5 & 56 & f & 17 & r Hemiparesis & & $\mathbf{s}$ & 92 & $\begin{array}{l}\text { Hemiparesis } \\
\text { (arm>leg) }\end{array}$ & 0 & 35 & $\begin{array}{l}\text { High blood pressure } \\
\text { rheumatic fever }\end{array}$ \\
\hline 6 & 34 & f & 5 & $\begin{array}{l}\text { r Hemiparesis, } \\
\text { apraxia and } \\
\text { transcortical aphasia } \\
\text { lack of initiative and } \\
\text { concentration } \\
\text { difficulties }\end{array}$ & $\begin{array}{l}1 \text { Superior } \\
\text { fronto-parietal }\end{array}$ & 1 & 86 & $\begin{array}{l}\text { Emiparesis } \\
\text { (leg }>>\text { arm) mild } \\
\text { perseveratio }\end{array}$ & 26 & 71 & $\begin{array}{l}\text { Angio: occ I } \\
\text { supramarginal a lupus } \\
\text { anticoagulant }\end{array}$ \\
\hline 7 & 53 & $\mathrm{~m}$ & 7 & 1 Hemiparesis & $\begin{array}{l}\text { r Anterior white } \\
\text { matter } \\
1 \text { Nucleus caudate }\end{array}$ & $\begin{array}{l}\mathbf{s} \\
\mathbf{s}\end{array}$ & 62 & Absent & 95 & 100 & $\begin{array}{l}\text { High blood pressure } \\
\text { Peripheral vascular } \\
\text { disease }\end{array}$ \\
\hline 8 & 64 & $\mathrm{~m}$ & 3 & 1 Hemiparesis & $\begin{array}{l}\text { r Internal capsule } \\
\text { r Fronto temporal }\end{array}$ & $\begin{array}{l}\mathbf{s} \\
\mathbf{s}\end{array}$ & 63 & Absent & 87 & 100 & $\begin{array}{l}\text { High blood pressure } \\
1982 \text { r CVA with fill } \\
\text { recovery previous } \\
\text { myocardial Infarction }\end{array}$ \\
\hline 9 & 49 & $\mathrm{~m}$ & 2 & \multirow{3}{*}{$\begin{array}{l}\text { 1 Ataxic hemiparesis } \\
\text { slurred speech } \\
\text { r Hemiparesis } \\
\text { (arm>>leg) } \\
\text { r hypoesthesia } \\
\text { aphasia }\end{array}$} & r Thalamic & $\mathbf{s}$ & 60 & Absent & 86 & 100 & Angiography: normal \\
\hline 10 & 52 & $\mathrm{~m}$ & 3 & & $\begin{array}{l}\text { 1 Fronto-temporo- } \\
\text { parietal }\end{array}$ & 1 & 55 & & 44 & 90 & \\
\hline & & & & & & & & $\begin{array}{l}\text { r Hypoesthesia } \\
\text { motor aphasia }\end{array}$ & & & Atrial fibrillation \\
\hline
\end{tabular}

indicate a severe plegia, from 33-64 a moderate paresis and 65-99 mild disability. Improvement in motor function was assessed by the raw score increment obtained at follow up examination relative to the initial assessment during the acute phase of the illness. Ratings were performed by one assessor throughout to obviate added variance resulting from interrater variability.

All patients had CT or MRI scanning on admission and, if necessary, this was repeated following recovery. Delayed CT or MRI scans were used to delineate the extent of the infarction. All images were reoriented so that the transverse slices lay parallel to the intercommissural plane. All the patients received standard medical treatment for their strokepatients $4,5,7,8$ and 10 received antihypertensive medication, none received $\mathrm{Ca}$ channel blockers, anticonvulsants, sedatives or anti-psychotics. Clinical data are summarised in table 1.

\section{PET studies}

PET was performed at a mean (SD) 4.9 (4.6) days from symptom onset and was repeated in the chronic phase [95.1 (48.7) days], following appreciable recovery of function. The ${ }^{15} \mathrm{O}$ inhalation method was used to measure cerebral blood flow (CBF), cerebral blood volume (CBV) and oxygen extraction (OER), from which the rate of oxygen consumption $\left(\mathrm{CMRO}_{2}\right)$ was calculated. ${ }^{15} 16$ Studies were carried out with an ECAT 931/8/12 (CTI, Knoxville) and performed at rest, in a quiet and dimly lit room with the patients' eyes closed and ears unplugged. During each study, head position was maintained by an individually moulded thermoplastic head holder. A short $21 \mathrm{~g}$ arterial line was placed into the radial artery at the onset of each study. The intrinsic spatial resolution of the scanner was $5.5 \times 5.5 \times 7.0 \mathrm{~mm}$ full-width at half maximum (FWHM), allowing the simultaneous collection of 15 contiguous transaxial planes. ${ }^{17}$ Reconstruction, attenuation correction (by measurement) and filtering resulted in images with a resolution of $8.5 \times 8.5 \times 7.0$ $\mathrm{mm}$ (FWHM). The set of data was then expanded by linear interpolation in the axial dimension to produce 43 transaxial slices with near cubic voxels of $2.05 \times 2.05 \times 2.5 \mathrm{~mm}$ allowing three dimensional inspection of scans visually. The scans were analysed on a computer (SUN 3/60) with image analysis software (ANALYZE, BRU, Mayo Clinic), which allowed them to be displayed relative to the intercommisural line (AC-PC line) and to be scaled for precise anatomical localisation by standard stereotactic coordinates based on the Talairach atlas. ${ }^{18-19}$ The procedure of reorienting PET scans was developed for normal studies but has been used successfully in studies of patients with cerebral infarcts.

\section{Data analysis}

In the acute phase of stroke a mismatch may occur between $\mathrm{CMRO}_{2}$ and $\mathrm{CBF}$ which manifests as a change in OER. ${ }^{7}$ For this reason, we analysed $\mathrm{CMRO}_{2}$ data which give a more direct reflection of tissue metabolism than CBF. Variability in the absolute levels of global $\mathrm{CMRO}_{2}$ between patients and between successive measurements in individuals averaged 9.4 $(4.8) \%$. Such variability was present in both the lesioned and unlesioned hemispheres and is in accordance with previous data. ${ }^{20-21}$ Even such small interscan variability may mask 
significant regional (r) $\mathrm{CMRO}_{2}$ changes. To circumvent this problem, and because we were primarily interested in variations in the regional profile of metabolism between the acute and recovered phases, we normalised the $\mathrm{rCMRO}_{2}$ data of the second scan of each patient to the average $\mathrm{CMRO}_{2}$ of the patient's first scan. Three features were analysed in the PET scans: 1) relative $\mathrm{rCMRO}_{2}$ changes in the anatomical area of the ischaemic lesion; 2) global $\mathrm{CMRO}_{2}$ changes occurring between the first and second scans in the group of patients; 3) relative $\mathrm{rCMRO}_{2}$ changes in individual patients.

1) Changes in the area of the lesion: To study the variations occurring in the area of the lesion, each pair of studies was aligned parallel to the AC-PC line. ${ }^{18}$ Irregular regions of interest (ROI) were drawn interactively, using the anatomical boundaries of the lesion shown on the similarly reoriented CT or MRI scan, onto the PET scan planes. The same ROIs were then automatically placed on the homologous slices of the follow up study. The average of the $\mathrm{rCMRO}_{2}$ value for the whole lesion so defined was compared with the average normalised $\mathrm{rCMRO}_{2}$ from the same region on the second scan for each patient.

2) Changes as a group: We used a descriptive and exploratory statistical approach to look for any general metabolic pattern associated with motor recovery. All the studies, irrespective of the site of the lesion were considered. The scans were flipped about the midsagittal plane such that all the ischaemic lesions were analysed as though left sided. All the scans were also resized by linear scaling into standardised brain dimensions. Data were smoothed by a square low-pass filter of size 9 pixels to improve the signal to noise and reduce variance due to differences in gyral anatomy between individuals. The presence of significant relative increases in $\mathrm{rCMRO}_{2}$ was assessed by constructing average pixel-by-pixel maps of the normalised $\mathrm{rCMRO}_{2}$ and associated variances for the first and the second scans and then comparing them by a $t$ test. In this way, areas of significant change were shown as an image of $t$ values thresholded for descriptive purposes at two levels: $p<0.01$ and $p<0.001$. The anatomical localisation of significantly changed areas was performed by simple cross reference to coordinates in the stereotaxic atlas of Talairach and Tournoux. ${ }^{19}$

3) Individual changes: To assess individual changes in relative $\mathrm{rCMRO}_{2}$ we considered each pair of studies matched anatomically by reference to the AC-PC line. Scans were smoothed, again to increase signal to noise, though less severely because of the absence of interindividual anatomical variation. Subtraction images were generated by taking the $\mathrm{CMRO}_{2}$ values of the first scan from the second, pixel-by-pixel. Only regions with increases spread over 4 contiguous pixels and anatomically associated with the motor system were considered further, that is, the primary motorsensory area, the premotor area, the supplementary motor area, the basal ganglia and the thalamus. Increases in normalised
$\mathrm{rCMRO}_{2}$ were quantified and expressed as percentage changes. The localisation of areas with an $\mathrm{rCMRO}_{2}$ increase was performed as above. Data from the cerebellar regions were not available from all patients and therefore are not analysed further in this paper.

In an attempt to describe with one variable both the extent and magnitude of relative $\mathrm{rCMRO}_{2}$ changes, we defined an index (oxygen metabolism index: OMI) from the product of the per cent normalised $\mathrm{rCMRO}_{2}$ increase in the region (calculated as the ratio of the average $\mathrm{rCMRO}_{2}$ between the second and the first scans) and the size of the contiguous area over which change was demonstrated (in pixels).

\section{Statistical analysis}

Changes in $\mathrm{rCMRO}_{2}$ and $\mathrm{OMI}$ values and clinical scores were analysed by intergroup comparisons using Student's $t$ test for paired and unpaired observations, linear regressions and Spearman rank correlations. Bonferroni corrections were used to adjust the threshold of significance for multiple comparisons.

\section{Results}

At the second examination, all patients demonstrated some recovery of motor function. The mean (SD) index of motor recovery (RI = MI at follow up - MI at entry), was 22 (15) $(+33 \%)$, ranging from +5 to +46 . The $M I$ at entry was positively correlated to the $\mathrm{MI}$ at follow up ( $r=0.91 ; p<0.0001)$, but there was no correlation between the RI and both the MI at entry or at follow up scanning. Three patients (1, 6 and 10) had large cortical lesions on CT or MRI, while the remaining seven had small infarcts with a maximum diameter less than $2.5 \mathrm{~cm}$. There were no statistically significant differences between the MI at entry or follow up, or of the RI between patients with small and large lesions.

In the lesion, a relative $\mathrm{rCMRO}_{2}$ increase was observed in all but three patients $(1,4$ and 5). On average, the $\mathrm{rCMRO}_{2}$ increase was 9 (17) $\%$. There was no correlation between the rCMRO2 changes at the site of lesion and the RI (fig 1). Statistical analysis failed to reveal a single pattern of $\mathrm{rCMRO}_{2}$ change for the

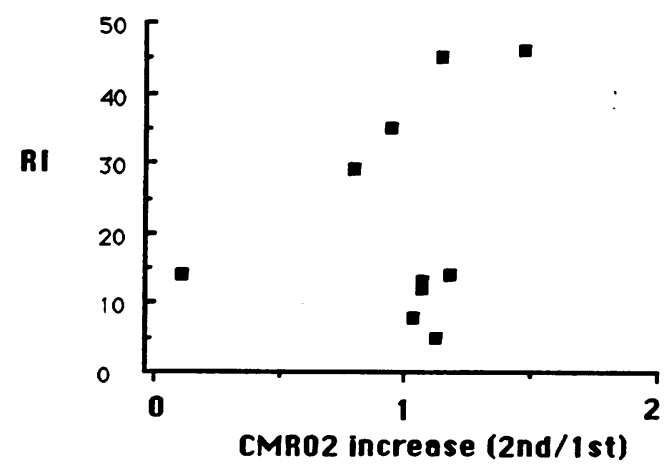

Figure 1 Variations of $\mathrm{CMRO}_{2}$ in the area of the anatomical lesion, as a ratio between the second and the first scan (abscissa) and the degree of improvement in motor function (RI). 
Table 2 Image subtraction analysis: $\mathrm{CMRO}_{2}$ changes after motor recovery evaluated as increases in the oxygen metabolism index (OMI) in cerebral regions normally associated with the generation of movements

\begin{tabular}{|c|c|c|c|c|c|c|c|c|c|c|}
\hline $\begin{array}{l}\text { Case } \\
\text { number }\end{array}$ & $C T$ or $M R I$ scan & $R I$ & Affected hemisphere regions & $I I / I$ & $n^{\circ}$ pixels & $O M I$ & Unaffected hemisphere regions & $I I / I$ & $n^{\circ}$ pixels & $O M I$ \\
\hline 1 & r Fronto-temporo-parietal & 12 & - & - & - & - & $\begin{array}{l}\text { supplementary motor area } \\
1 \text { motorsensory area }\end{array}$ & $\begin{array}{l}1 \cdot 35 \\
1 \cdot 20\end{array}$ & $\begin{array}{l}33 \\
76\end{array}$ & $\begin{array}{l}44 \cdot 55 \\
91 \cdot 36\end{array}$ \\
\hline 2 & r Internal capsule & 8 & basal ganglia & 1.63 & 20 & $32 \cdot 56$ & - & - & - & - \\
\hline 3 & r Internal capsule & 29 & $\begin{array}{l}1 \text { motorsensory area } \\
\text { supplementary motor area } \\
\text { basal ganglia }\end{array}$ & $\begin{array}{l}1 \cdot 28 \\
1 \cdot 16 \\
1 \cdot 26 \\
1 \cdot 37\end{array}$ & $\begin{array}{l}80 \\
16 \\
16 \\
16\end{array}$ & $\begin{array}{r}102 \cdot 40 \\
18 \cdot 56 \\
17 \cdot 26 \\
21 \cdot 92\end{array}$ & $\begin{array}{l}1 \text { motorsensory area } \\
\text { supplementary motor area } \\
\text { premotor area } \\
\text { thalamus }\end{array}$ & $\begin{array}{l}1 \cdot 25 \\
1 \cdot 18 \\
1 \cdot 38 \\
1 \cdot 62\end{array}$ & $\begin{array}{l}16 \\
16 \\
32 \\
32\end{array}$ & $\begin{array}{l}20 \cdot 00 \\
18 \cdot 88 \\
44 \cdot 16 \\
51 \cdot 84\end{array}$ \\
\hline 4 & $\begin{array}{l}\text { r Internal capsule and } \\
\text { thalamus } \\
(\mathrm{MRI})\end{array}$ & 14 & - & - & - & - & $\begin{array}{l}\text { thalamus } \\
\text { basal ganglia } \\
1 \text { motorsensory area }\end{array}$ & $\begin{array}{l}1.45 \\
1 \cdot 34 \\
1 \cdot 32\end{array}$ & $\begin{array}{l}16 \\
48 \\
76\end{array}$ & $\begin{array}{l}23 \cdot 20 \\
64 \cdot 16 \\
99 \cdot 96\end{array}$ \\
\hline 5 & $\begin{array}{l}\text { I corona radiata } \\
\text { r white matter "lucencies" } \\
\text { (MRI) }\end{array}$ & 35 & $\begin{array}{l}1 \text { motorsensory area } \\
\text { basal ganglia } \\
\text { thalamus }\end{array}$ & $\begin{array}{l}1 \cdot 23 \\
1 \cdot 30 \\
1 \cdot 48\end{array}$ & $\begin{array}{l}16 \\
16 \\
32\end{array}$ & $\begin{array}{l}19 \cdot 68 \\
20 \cdot 80 \\
47 \cdot 36\end{array}$ & $\begin{array}{l}1 \text { motorsensory area } \\
\text { premotor area }\end{array}$ & $\begin{array}{l}1 \cdot 26 \\
1 \cdot 82\end{array}$ & $\begin{array}{l}32 \\
16\end{array}$ & $\begin{array}{l}40 \cdot 32 \\
29 \cdot 12\end{array}$ \\
\hline 6 & 1 fronto-parietal & 45 & $\begin{array}{l}\text { supplementary motor area } \\
1 \text { motorsensory area } \\
\text { thalamus }\end{array}$ & $\begin{array}{l}1 \cdot 75 \\
1.47 \\
1.41\end{array}$ & $\begin{array}{r}112 \\
112 \\
16\end{array}$ & $\begin{array}{r}195.84 \\
164 \cdot 48 \\
22 \cdot 56\end{array}$ & $\begin{array}{l}\text { basal ganglia } \\
\text { premotor area } \\
\text { thalamus }\end{array}$ & $\begin{array}{l}1 \cdot 50 \\
1 \cdot 23 \\
1 \cdot 21\end{array}$ & $\begin{array}{l}52 \\
16 \\
16\end{array}$ & $\begin{array}{l}77 \cdot 62 \\
19 \cdot 68 \\
19 \cdot 36\end{array}$ \\
\hline 7 & $\begin{array}{l}r \text { anterior white matter } \\
\mathrm{I} \text { nucleus caudatus }\end{array}$ & 5 & - & - & - & - & - & - & - & - \\
\hline 8 & $\begin{array}{l}\text { r Internal capsule } \\
\text { I Fronto-temporal }\end{array}$ & 13 & 1 motorsensory area & $1 \cdot 57$ & 16 & $25 \cdot 12$ & \multirow{2}{*}{$\begin{array}{l}\text { supplementary motor area } \\
1 \text { motorsensory area } \\
\text { thalamus } \\
1 \text { motorsensory area } \\
\text { basal ganglia } \\
\text { supplementary motor area } \\
1 \text { motorsensory area }\end{array}$} & \multirow{2}{*}{$\begin{array}{l}1 \cdot 34 \\
1.35 \\
2 \cdot 17 \\
1.44 \\
1 \cdot 31 \\
1.44 \\
1 \cdot 25\end{array}$} & \multirow{2}{*}{$\begin{array}{r}128 \\
32 \\
20 \\
96 \\
32 \\
32 \\
32\end{array}$} & \multirow{2}{*}{$\begin{array}{r}170 \cdot 88 \\
43 \cdot 20 \\
43 \cdot 40 \\
138 \cdot 56 \\
41 \cdot 92 \\
45 \cdot 92 \\
39 \cdot 84\end{array}$} \\
\hline 10 & fronto-temporo-parietale sn & 46 & $\begin{array}{l}1 \text { motor sensory area } \\
\text { supplementary motor area }\end{array}$ & $\begin{array}{l}1 \cdot 31 \\
1 \cdot 37\end{array}$ & $\begin{array}{l}64 \\
16\end{array}$ & $\begin{array}{l}83.68 \\
21.92\end{array}$ & & & & \\
\hline
\end{tabular}

group of patients as a whole and for patients grouped according to the size of the ischaemic lesion.

The results of individual analyses of changes in motor associated areas are reported in table 2. The magnitude and extent of metabolic improvement did not correlate with $\mathrm{MI}$ scores at entry or at follow up. The change in OMI did not differ between patients with large and small ischaemic lesions in either the affected or unaffected cerebral hemispheres, neither regionally nor globally.

A correlation between the $\mathrm{RI}$ and the $\mathrm{OMI}$ in cerebral regions associated with motor control was observed in the affected hemisphere $(r=0.75 ; p<0.01)$ (fig 2). No correlation was found between motor recovery and metabolic increases in the unaffected hemisphere or in the motor areas of both sides of the brain pooled. There was no significant difference in the OMI between the two cerebral hemispheres.

We also analysed the different individual patterns of $\mathrm{rCMRO}_{2}$ change (table 3 ). In the cortex one patient showed an increase in the

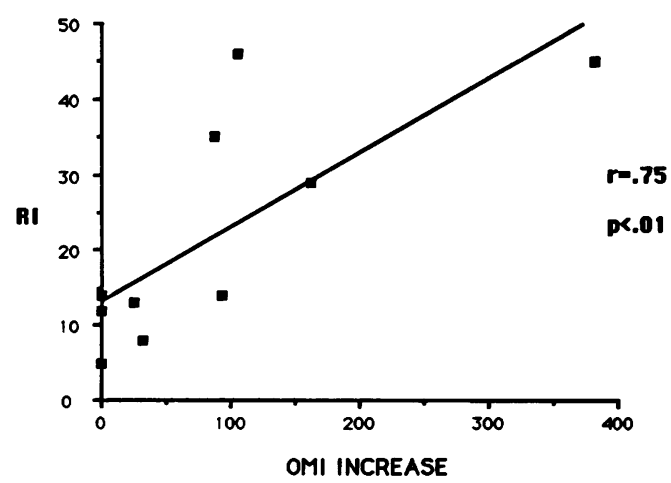

Figure 2 Correlation between the increase in the oxygen metabolism index (OMI) in motor areas of the affected cerebral hemisphere and the degree of improvement of motor function $(R I)$. affected hemisphere (patient 6), four in both affected and contralateral hemispheres (patients 3, 5, 9 and 10), three in the contralateral hemisphere alone (patients 1, 4 and 8) and two showed no cortical change (patients 2 and 7). Greater improvement of motor function was observed in patients in which there was a mean (SD) OMI increase in the affected hemisphere [RI $=34$ (13)] than in patients in which the increase in OMI was absent, or present only in the contralateral hemisphere $[R I=10$ (4)]; $p<0.005)$. Furthermore, patients with a relative cortical $\mathrm{CMRO}_{2}$ increase in the unaffected hemisphere only $[R I=13(1)]$ recovered better than patients without cortical metabolic change [RI $=7$ (2)]; $\mathrm{p}<0.01$ ).

Patient 5 was a 56 year old women who presented with a sudden onset of right hemiplegia without language or sensory deficit. The MI was 0 . In the past medical history she had rheumatic fever, hypertension and a family history of stroke. On admission, chest radiographs and ECG were normal. Doppler sonography was normal. Echocardiography showed mitral valve prolapse. The CT scan showed a hypodense lesion in the left corona radiata. Later, an MRI scan showed an hyperintense area in the left corona radiata and scattered "lucencies" in the white matter. The PET scan showed reduced metabolism in the area of the lesion and, of lower magnitude, in the left frontoparietal cortex.

At follow up, the patient had improved, with a mild residual right hemiparesis affecting the upper more than the lower limb. She was able to walk and the MI was 35 . The PET scan showed persistence of reduced metabolism in the damaged area. Subtraction imaging showed an increase of oxygen metabolism in the primary motorsensory area, the premotor area, the basal ganglia and the thalamus of the affected hemisphere. A metabolic increase was found in the primary motorsensory area and the premotor area in the contralateral hemisphere (fig 3). 
Table $3 \mathrm{CMRO}_{2}$ changes in the brain after motor recovery expressed as increases in the oxygen metabolism index (OMI). The subcortical structures included the basal ganglia and thalamus

\begin{tabular}{|c|c|c|c|c|c|c|}
\hline \multirow[b]{2}{*}{$\begin{array}{l}\text { Case } \\
\text { number }\end{array}$} & \multicolumn{2}{|l|}{ Global } & \multicolumn{2}{|l|}{ Cortical } & \multicolumn{2}{|c|}{ Sub-cortical } \\
\hline & $\begin{array}{l}\text { Affected } \\
\text { hemisphere }\end{array}$ & $\begin{array}{l}\text { Unaffected } \\
\text { hemisphere }\end{array}$ & $\begin{array}{l}\text { Affected } \\
\text { hemisphere }\end{array}$ & $\begin{array}{l}\text { Unaffected } \\
\text { hemisphere }\end{array}$ & $\begin{array}{l}\text { Affected } \\
\text { hemisphere }\end{array}$ & $\begin{array}{l}\text { Unaffected } \\
\text { hemisphere }\end{array}$ \\
\hline 1 & 0 & 136 & 0 & 136 & 0 & 0 \\
\hline 2 & 32 & 0 & 0 & 0 & 32 & 0 \\
\hline 3 & 163 & 135 & 121 & 83 & 42 & 52 \\
\hline 4 & 0 & 187 & 0 & 100 & 0 & 87 \\
\hline 5 & 88 & 69 & 20 & 69 & 68 & 0 \\
\hline 6 & 382 & 117 & 360 & 20 & 22 & 97 \\
\hline 7 & 0 & 0 & 0 & 0 & 0 & 0 \\
\hline 8 & 25 & 214 & 25 & 214 & 0 & 0 \\
\hline 9 & 93 & 182 & 93 & 139 & 0 & 43 \\
\hline 10 & 106 & 128 & 106 & 86 & 0 & 42 \\
\hline
\end{tabular}

Discussion

Restoration of function is a complex phenomenon that depends on various factors such as the nature of the affected function, the location and extent of the lesion, residual neuronal viability in damaged brain structures and the capability of other anatomical structures to assume the functions of damaged regions.

We did not observe a unique pattern of relative metabolic changes at rest that were related to motor recovery in our group of patients or in subgroups based on the size of the ischaemic lesions. This is not surprising because of heterogeneity in the patient population which represents one of the main problems in the investigation of stroke patients in general. To partially circumvent this, we focused our analysis on the motor deficit and the relative metabolic changes in brain areas primarily involved in motor function. We were aided in interpreting the metabolic changes by the absence of correlation between the extent of motor recovery (RI) and the severity of initial motor dysfunction in our patients. This allowed use of the $\mathrm{RI}$ as an index of motor recovery, whatever the initial clinical presentation. Likewise, motor recovery was not related to any relative metabolic changes at the site of the lesion. Similar results were obtained by

Figure 3 The figure shows changes in $\mathrm{CCMRO}$ in patient 5 . There is a bilateral increase of metabolism in the primary motorsensory areas in both hemispheres and in the premotor cortex on the unaffected side. Upper row-first PET scan; middle row- second PET scan; lower row-image subtraction: tomographic level is 5 to $6 \mathrm{~cm}$ above the $A C-P C$ line.
Hakim et $a^{21}$ who reported $\mathrm{rCMRO}_{2}$ changes occurring in the core of the ischemic lesion and in the "penumbra" area, in a randomised study of the effects of nimodipine in patients with acute stroke. Despite different patterns of metabolic changes in these two areas $(+24.4 \%$ and $+18.8 \%$ in the treated group and in $-17 \cdot 1 \%$ and $-12 \cdot 4 \%$ in the untreated one), the authors did not observe any differences in outcome between the two groups. Our study and that of Hakim et al scanned patients relatively acutely, but at a stage when low OER indicated that ischaemic infarction had already occurred. ${ }^{7}$ It is therefore not surprising that we found no significant correlation between functional recovery and relative metabolic changes in the infarct itself.

We have, however, observed a correlation between motor recovery and the mean relative increase of metabolism in cerebral regions involved in motor function in the affected hemisphere and in particular in the cortex. Thus our data suggest that the degree of relative metabolic improvement in intact areas functionally connected to the site of ischaemic damage may be correlated with the magnitude of clinical improvement. The occurrence of functional changes in the nervous system at sites remote from the primary lesion has been named diaschisis. ${ }^{22}$ Feeney and Baron ${ }^{23}$ reviewed the occurrence of diaschisis with various brain lesions and discussed its contribution to the clinical deficit. Evidence suggests a correlation between reversal of remote effects and recovery. After selective cortical ablations Dauth et $a l^{24}$ and Deuel ${ }^{25}$ observed hypometabolism in a number of cortical and subcortical areas undamaged by lesions and subsequent regression with recovery. Many authors ${ }^{26-30}$ have described clinical recovery and concurrent increases of cortical metabolism or blood flow in patients with subcortical lesions. Finally, in acute stroke, Kushner et $a l^{31}$ have shown that the degree of glucose hypometabolism in the infarct and the surrounding, structurally intact cortex (as judged by structural imaging) is inversely related to the extent of eventual recovery.

Our results also suggest that in some cases there may be a role for the unaffected hemisphere in the recovery process. Generally we observed similar relative metabolic increases in the cerebral hemispheres between the first and the second scans, but patients without an increase in the lesioned, but an increment in the unaffected hemisphere seemed to recover more than patients without cortical metabolic changes in either. There is clinical and experimental evidence to suggest a role for the ipsilateral hemisphere in recovery and there are also dramatic clinical reports of functional recovery following hemispherectomy. ${ }^{32-33}$ Other investigators have demonstrated deficits in fine motor control and speed of execution of hand movements on the side ipsilateral to cortical lesions. ${ }^{34-37}$

A direct ipsilateral corticospinal projection has been suggested by experimental studies with unilateral spinal cord or cerebral peduncular lesions. ${ }^{38}$ This phenomenon is evident 
only after a lesion because the ipsilateral pathways are probably suppressed when the crossed contralateral system is intact. ${ }^{39}$ The role of cross-talk between the hemispheres may be a crucial component of this mechanism. Crowne et $a^{40}$ found that monkeys that recovered from acute neglect after frontal eye field lesions redeveloped neglect after callosal section. Watson et $a^{41}$ demonstrated that neglect after unilateral frontal lesions was more severe in monkeys who had previously undergone callosal section. Steiner and Melamed ${ }^{42}$ observed that ipsilateral eye deviation after unilateral hemispheric stroke usually persists for a few days, but may persist for weeks if there has been previous damage to the other hemisphere.

Further evidence for the role of ipsilateral structures in the recovery of function comes from the work of Yamaguchi et $a l^{43}$ who showed a focal rCBF increase in the right hemisphere in a region homologous to Broca's area during verbalisation following recovery from aphasia. Levine et $a l^{44}$ showed that the rate and extent of improvement from left spatial neglect in patients was dependent on the integrity of remaining areas in both cerebral hemispheres, as assessed by the presence of atrophy at CT scan. Recently, Chollet et al ${ }^{45}$ have performed PET CBF activation studies in patients with recovery from ischaemic hemiparesis. They demonstrated strict lateralisation of focal cortical responses when the normal hand was used, but bilateral foci on movement of the recovered, previously paretic hand.

In conclusion, we observed a relative increase of oxygen metabolism in the lesioned hemisphere in all our patients, affecting the primary lesion and/or areas apparently undamaged by the primary ischaemic insult. The cortical increases correlated with recovery. Motor recovery was least pronounced in those without demonstrable increase in relative cortical oxygen metabolism, intermediate in those with increases in the cortex of the unlesioned side alone and most marked in those with increases in the appropriate, but lesioned hemisphere also. This pattern suggests that motor recovery may be due to the development of new functional connections between brain areas generally associated with motor function. Thus motor recovery is a complex phenomenon in which the lesioned site and other cortical and subcortical areas (in ipsilateral and contralateral hemispheres) that together constitute the distributed neuronal network that normally subserves movement, interplay to help reverse the deficit caused by the infarct. The conclusions of our study must be qualified by the number of patients, the heterogeneity of clinical presentation and the use of steady-state techniques which permit only single estimations of metabolism at one scanning session.

Metabolism is a more direct index of transsynaptic activity than cerebral blood flow. However, rCBF can be used effectively to monitor changes of metabolism during activation, whereas $\mathrm{rCMRO}_{2}$ appears uncoupled from local glucose metabolism (rCMRGlu) under these conditions. $^{46}$ In addition
rCMRGlu cannot be measured rapidly. This explains why this is the first attempt at a regional analysis of the relative profiles of resting $\mathrm{rCMRO}_{2}$ in patients recovering from stroke.

We thank the Radiochemistry and PET Methods Sections of the MRC Cyclotron Unit and Miss C Taylor and Mr P Bloomfield for their invaluable help in scanning and analysis. We also thank Dr DJ Brooks and Dr RJS Wise for referring We also thank Dr DJ Brooks and Dr RJS Wise for referring
patients. Dr Di Piero was funded by the Italian CNR and Dr patients. Dr Di Piero was funded by the Italia

1 Dombovy ML, Bach-y-Rita P. Clinical observations on recovery from stroke. In: Waxman GS, ed. Advances in neurology, vol 47: functional recovery in neurological disease. neurology, vol 47: functional recovery in neut

2 Jackson JH. Remarks on the diagnosis and treatment of diseases of the brain. $B M \mathcal{F}^{1988 ; 2: 59-63}$.

3 Hier DB. Mondlock J. Caplan LR. Recovery of behavioral abnormalities after right hemisphere stroke. Neurology 1983;33:345-50.

4 Schenkman M, Butler RB, Naeser MA, Kleefield J. Cerebral hemisphere asymmetry in CT and functional recovery from hemiplegia. Neurology 1983;33:473-7.

5 Knopman DS, Rubens AB. The validity of computed tomographic scan findings for the localization of cerebral functions. The relationship between computed tomography and hemiparesis. Arch Neurol 1986;43:328-32.

6 Lassen NA. The luxury-perfusion syndrome and its possible relation to acute metabolic acidosis localised within the relation to acute metabolic acid

7 Wise RJS, Bernardi S, Frackowiak RSJ, Legg NJ, Jones T. Serial observations on the pathophysiology of acute stroke. Brain 1983;106:197-222.

8 Frackowiak RSJ, Lammertsma AA. Clinical measurement of cerebral blood flow and oxygen consumption. In: Reivich M, Alavi A, eds. Positron emission tomography. New York: Alan R Liss, 1985:153-81.

9 Burke AM, Younkin D, Gordon J, et al. Changes in cerebral blood flow and recovery from acute stroke. Stroke 1986;17:173-8.

10 Lenzi GL, Pantano P, Di Piero V, et al. Regional cerebral perfusion and its relationship with clinical and morphological findings in patients studied within six hours after ischemic stroke. $f$ Cereb Blood Flow Metab 1987;7 (Suppl 1):S199.

11 Giubilei F, Lenzi GL, Di Piero V, et al. Predictive value of cerebral blood flow in acute stroke. Stroke 1990; 21:895-900.

12 Demeurisse G, Demol O, Robaye E. Motor evaluation in vascular hemiplegia. Eur Neurol 1980;19:382-9.

13 Mahoney FJ, Barthel DW. Functional evaluation: the Barthel index. Md St Med $f$ 1965;14:61-5.

14 Folstein MF, Folstein SE, McHugh PR. "Mini Mental State": a practical method for grading the cognitive state of patients for the clinicians. 7 Psychiatr Res 1975 12:189-98.

15 Frackowiak RSJ, Lenzi GL, Jones T, Heather JD. Quantitative measurement of regional cerebral blood flow and oxygen metabolism in man using $\mathrm{O}$ and positron emission tomography: Theory, procedure and normal values. $f$ tomography: Theory, procedure and

16 Lammertsma AA. Jones T. Correction for the presence of intravascular oxygen-15 in the steady-state technique for measuring regional oxygen extraction ratio in the brain: 1 . Description of the method. $f$ Cereb Blood Flow Metabol 1983;3:416-24.

17 Spinks T. Guzzardi R. Bellina CR. Performance characteristics of a whole body positron tomograph. $₹ \mathrm{Nucl} \mathrm{Med}$ 1988;29:1833-41.

18 Friston KJ, Passingham RE, Nutt JG, Heather JD, Sawle GV, Frackowiak RSJ. Localisation in PET images: direct fitting of the intercommisural (AC-PC) line. $\mathcal{f}$ Cereb Blood Flow Metabol 1989;9:690-5.

19 Talairach J, Tournoux PJ, eds. Co-planar stereotaxic atlas of the human brain. New York: Thieme, 1988.

20 Lenzi GL, Frackowiak RSJ, Jones T, Heather JD, Lammertsma AA, Rhodes CG, Pozzilli C. CMRO and CBF by the Oxygen-15 inhalation technique. Eur Neurol by the Oxygen-15

21 Hakim AM, Evans AC, Berger L, et al. The effect of nimodipine on the evolution of human cerebral infarction studied by PET. I Cereb Blood Flow Metab 1989;9 523-34.

22 von Monakow C. Diaschisis (1914 article translated by G Harris) In: Pribram KH, ed. Brain and behaviour I: mood states and mind. Baltimore: Penguin: 1969:27-36.

23 Feeney DM, Baron JC. Diaschisis. Stroke 1986; 17:817-30.

24 Dauth GW, Gilman S, Frey KA, Penney JB. Basal ganglia glucose utilization after recent precentral ablation in the monkey. Ann Neurol 1985;17:431-8.

25 Deuel RK. Neural dysfunction during hemineglect after cortical damage in two monkey models. In: Jeannerod $\mathbf{M}$, ed. Neurophysiological and Neuropsychological aspects of ed. Neurophysiological and Neuropsychological aspests of
spatial neglect. Amsterdam: Elsevier Science Publishers spatial neglect.

26 Baron JC, D'Antona R, Pantano P, Serdaru M, Samson Y, Bousser MG. Effects of thalamic stroke on energy 
metabolism of the cerebral cortex. Brain 1986; 109:1243-59.

27 Knopman DS, Rubens AB, Selnes OA, Klassen AC, Meyer MW. Mechanisms of recovery from aphasia: evidence from serial Xenon-133 cerebral blood flow studies. Ann Neurol 1984:15:530-5.

28 Demeurisse G, Capon A. Language recovery in aphasic stroke patients: clinical, CT and CBF studies. Aphasiology stroke patients:

29 Vallar G, Perani D, Cappa SF, Messa C, Lenzi GL, Fazio F. Recovery from aphasia and neglect after subcortical stroke: neuropsychological and cerebral perfusion study. $\mathcal{f}$ Neurol Neurosurg Psychiatry 1988;51:1269-76.

30 Perani D, Di Piero V, Lucignani G, et al. Remote effects of subcortical cerebrovascular lesions: a SPECT cerebral perfusion study. F Cereb Blood Flow Metab 1988; 8:560-7.

31 Kushner M, Reivich M, Fieschi C, et al. Metabolic and clinical correlates of acute ischemic infarction. Neurology 1987;37:1103-10.

32 Gardner WJ. Removal of right cerebral hemisphere for infiltrating glioma. $\mathfrak{f} A M A$ 1933;101:823-6.

33 Glees $P$. Functional reorganization following hemispherectomy in man and small experimental lesions in primates. In: Bach-y-Rita P, ed. Recovery of function: theoretical considerations for brain injury rehabilitation. Bern: Hans Huber, 1980:106-26.

34 Brodal A. Self-observation and neuroanatomical considerations after a stroke. Brain 1973;96:675-94

35 Hebson RH. Griffith ER. Long WE. Fowler R. Function of the normal hand in stroke patients. Arch Phys Med Rehabil 1971;52:170-4.

36 Brinkman J; Kuypers HJGM. Cerebral control of contralateral and ipsilateral arm, hand, and finger movements

in the split-brain rhesus monkeys. Brain 1973;96: in the
37 Jones RD, Donaldson IM, Parkin PJ. Impairment and recovery of ipsilateral sensory-motor function following unilateral cerebral infarction. Brain 1989;112:113-32.

38 Bucy PC, Ladpli R, Ehrlich A. Destruction of the pyramidal tract in the monkey: the effects of bilateral section of the cerebral peduncles. $f$ Neurosurg $1966 ; 25: 1-23$.

39 Gazzaniga MS, Bogen JE, Sperry W. Dyspraxia following division of the cerebral commissures. Arch Neurol 1967;16:606-12.

40 Crowne DP, Yeo $\mathrm{CH}$, Russell IS. The effects of unilateral frontal eye field lesions in the monkey: visual motor guidance and avoidance behavior. Behav Brain Res 1981;2:165-87.

41 Watson RT, Valenstein E, Day AL, Heilman KM. The effect of corpus callosum lesions on unilateral neglect in monkeys. Neurol 1984;34:812-5.

42 Steiner I, Melamed E. Conjugate eye deviation after acute hemisphere stroke: delayed recovery after previous contralateral frontal lobe damage. Ann Neurol 1984. 19:509-11

43 Yamaguchi F, Meyer JS, Sakai F, Yamamoto M. Case reports of three patients to illustrate rCBF responses reports of three patients to illustrate rCBF responses
during behavioral activation. Brain Lang 1980; 9:145-58.

44 Levine DN, Warach JD, Benowitz L, Calvanio R. Left spatial neglect: effects of lesion size and premorbid brain atrophy on severity and recovery following right cerebral infarction. Neurol 1986;36:362-6.

45 Chollet F, Di Piero V, Wise RJ, Brooks DJ, Dolan RJ, Frackowiak RSJ. The functional anatomy of motor recovery after stroke in humans. Ann Neurol 1991; 29:63-71.

46 Fox PT, Raichle ME. Focal physiological uncoupling of cerebral blood flow and oxidative metabolism during somatosensory stimulation in human subjects. Proc Natl Acad Sci USA 1986;83:1140-4. 